\title{
Comparison of Nonphaco small incision Cataract Surgery with Conventional Method: An Observational Study
}

\author{
Shamima Sultana ${ }^{1}$, AQM Omar Sharif ${ }^{2}$, Nazneen Begum³ ${ }^{3}$ Salma Parveen ${ }^{4}$, \\ Wahida Begum 5 , MM Ehsanul Haque ${ }^{6}$ \\ ${ }^{1}$ Assistant Professor ( Eye), National Institute of Ophthalmology \& Hospital, Dhaka, Bangladesh; ${ }^{2}$ Junior Consultant, Department of \\ Ophthalmology, Shaheed Suhrawardy Medical College \& Hospital, Dhaka, Bangladesh; ${ }^{3}$ Senior Consultant (Eye), National Institute of \\ Ophthalmology \& Hospital, Dhaka, Bangladesh; ${ }^{4}$ Senior Consultant, Central Police Hospital, Dhaka, Bangladesh; ${ }^{5}$ Associate \\ Professor, Department of Neuroradiology \& Imaging, National Institute of Neurosciences \& Hospital, Dhaka, Bangladesh; \\ ${ }^{6}$ Professor, Department of Neurosurgery, Chittagong Medical College, Chittagong, Bangladesh
}

[Received: 12 April 2019; Accepted: 20 May 2019; Published: 1 July 2019]

\begin{abstract}
Background: Cataract surgery is very important for the correction of visual acuity among the patients. Objective: The purpose of the present study was to assess the uncorrected visual acuity in small incision cataract surgery (SICS) with PCIOL than conventional method of ECCE with PCIOL implantation. Methodology: This cross-sectional study was conducted at National Institute of Ophthalmology, Dhaka, Bangladesh from January 1999 to December 2000 for a period of two (02) years. Patients with senile cataract were selected for study. A comparative study of changes in postoperative visual outcome and refractive status during post-operative follow up period up to 2 months were observed and documented between two groups of patients, one with suture less nonphaco SICS with PCIOL another with conventional ECCE with PCIOL. All the cataract surgery were done by the same surgeon, and in same place. All the patients were examined carefully both pre and post-operatively. For the purpose of recording, a proforma was made that includes particulars of the patient, complete history, general examination, ocular examination, relevant investigations, operation note, perioperative complications, post-operative follow-up, pre and post-operative visual acuity with keratometric reading. Result: A total of 60 eyes of cataract patients were included in the study of which 30 eyes of cataract patients were randomly selected for suture less nonphaco SICS with PCIOL and 30 eyes of cataract patients were for conventional ECCE with PCIOL.Mean age distribution $(58.83 \pm 5.55$ and $58.77 \pm 6.56)$ was similar in both groups. The unaided vision in both SICS \& ECCE group at different postoperative intervals was reported. At day 7 and month 1 postoperatively the result appears highly significant between the two groups. At day 1 and month 2 also shows the significant result between the 2 groups. The best corrected visual acuity in SICS and ECCE group at different postoperative intervals was measured. At day 7 and month 1 postoperatively the result appears highly significant between the two groups. At day 1 and month 2 also shows the significant result between the 2 groups.In SICS group out of 30 patients, $7(23.3 \%)$ cases acquired unaided vision $6 / 9$ at day $1,10(33.3 \%)$ patients at day 7,14(46.6\%)patients at month 1 and 15(49.9\%) patients at month 2. On the other hand in ECCE group no patient was found with vision $\geq 6 / 9$ at day 1 and only one patient with vision $\geq 6 / 9$ at day 7 .At month 1 there were $5(16.6 \%)$ patients, and at month 2 there were $9(29.9 \%)$ patients with vision $\geq 6 / 9$. Nearly $50.0 \%$ patients of SICS group achieve unaided vision of $\geq 6 / 9$ within the follow up period of 02 months. Conclusion: In conclusion Uncorrected visual acuity in SICS cases were better than that of ECCE cases with sutures. [Journal of National Institute of Neurosciences Bangladesh, 2019;5(2): 185-190]
\end{abstract}

Keywords: types of cataract; grades of cataract; visual acuity

Correspondence: Dr.Shamima Sultana; Assistant Professor ( Eye), National Institute of Ophthalmology \& Hospital, Sher-E-Bangla Nagar, Agargaon, Dhaka-1207, Bangladesh; Email: sshamima2002@gmail.com;Cell No.:+8801729232923

Conflict of interest: There is no financial conflict of interest relevant to this paper to disclose.

Funding agency: This research project was not funded by any group or any institution.

Contribution to authors: Sultana S, Sharif AQMO, Begum Ncontributed from the protocol preparation, data collection up to report writing. Manuscript writing was performed by Sultana S. Parveen S, Begum W, Haque MMEhelped in statistical model selection and analysis. Sultana $\mathrm{S}$ has revised the manuscript.

How to cite this article: Sultana S, Sharif AQMO, Begum N, Parveen S, Begum W, Haque MME.Comparison of Nonphaco small incision Cataract Surgery with Conventional Method: An Observational Study. J NatlInstNeurosci Bangladesh, 2019;5(2): 185-190 Copyright: (02019. Sultana et al. Published by Journal of National Institute of Neurosciences Bangladesh. This article is published under the Creative Commons CC BY-NC License (https://creativecommons.org/licenses/by-nc/4.0/). This license permits use, distribution and reproduction in any medium, provided the original work is properly cited, and is not used for commercial purposes. 


\section{Introductio}

Evolution of cataract surgery in the past five decades is tremendous in Bangladesh. Extracapsular cataract extraction (ECCE) was the routine procedure for extraction of lenses ${ }^{1}$ but afterward intracapsular cataract extraction of lens becomes popular to avoid complication of $\mathrm{ECCE}^{2}$. The postoperative optical correction in both ICCE and ECCE is made with thick lens, which results in marked visual problems. The contact lens ameliorates some of the problems but $7.0 \%$ magnification still remains in unilateral cataract causing aniseikonia ${ }^{3}$.

Technology has broadened the surgical pattern from ICCE camp surgeries, simple ECCE, ECCE with IOL to phaco or SICS with foldable or rigid posterior chamber intraocular lens implantation ${ }^{4}$. With the advancement of the operating microscope, finer microsurgical instruments and improved technique, ECCE with posterior chamber lens implantation has now become routine procedure. The visual recovery after surgery may beimpaired due to various operative and postoperative factors. And the ultimate limiting factor in optimum postoperative visual function is often the amount of postoperative corneal astigmatism, which is commonly faced in conventional extaacapsular cataract extraction ${ }^{5}$. Small incision phacoemulsification cataract surgery has the potential to reduce postoperative astigmatism and hasten visual rehabilitation ${ }^{6}$. In thisrespectphacoemulsification started in Bangladesh since middle of nineties only about six years back. In this procedure cataract surgery can be done as day case and in some cases only one day of hospitalization is sufficient, no stitch is required, less convalescence period and almost no visual discomfort to patient. In a developing country, with limited resources and more problems, phacoemulsification may not be the surgery for the mass people but to provide the comparable advantage to phaco-emulsification, small incision cataract surgery (SICS) developed ${ }^{7}$. Like phaco, the advantages over conventional method of ECCE with PCIOL are self-sealing small incision, rapid wound healing, short convalescence period and early stabilization of induced astigmatism. Moreover nonphaco SICS is less expensive and easily accessible and affordable for the community people and can be practiced both in urban and rural areas in a developing country8.

Considering the situation in rural aspect of Bangladesh a comparative study between small incision cataract extraction with PCIOL and conventional method of extracapsular cataract extraction with PCIOL was done and every effort had been made to evaluate and compare the postoperative visual outcome and refractive status.
Therefore this present study was undertaken to assess the uncorrected visual acuity in small incision Cataract Surgery (SICS) with PCIOL than conventional method of ECCE with PCIOL implantation.

\section{Methodology}

This prospective comparative cross-sectional study was done. This present study was conducted at National Institute of Ophthalmology, Dhaka, Bangladesh from January 1999 to December 2000 for a period of two (02) years. Senile cataract with functional disability fully accounted for by cataract formation and not for other ocular pathology were included for this study. Patients with other associated ocular disease, preexisting corneal lesion, cataract other than senile type, history of previous ocular surgery in the same eye and patients not attending in all the follow-up visits were excluded from the study. Cataract patients were included in the study and were randomly selected for suture less nonphaco SICS with PCIOL and conventional ECCE with PCIOL. Preoperative visual acuity was measured and postoperative unaided and best corrected visual acuity were measured at day 1 , day 7, month 1 and month 2. Preoperative keratometric astigmatism and postoperative keratometric astigmatism were checked at month 2. Proforma contained findings of preoperative ocular examinations, operation note, any preoperative complications, postoperative follow-up including postoperative uncorrected visual acuity, visual acuity with pinhole best corrected visual acuity, postoperative keratometric cylindrical value and post-operative refraction. In both SICS and ECCE group surgery were done by same surgeon and same surgical technique. Both conventional extracapsularcataract extraction (ECCE) and nonphacosmall incision cataract surgery (SICS) were performed under local anesthesia. Finally the operated eye was dressed with eye pad and bandage. After SICS with PCIOL implantation the operated eye was opened after $24 \mathrm{hrs}$. Topical steroid and antibiotic drops were given 4 hourly for 6 weeks. The patient was discharged on 2 nd postoperative day. All the patients were followed at day 1, day7, month 1 and month 2 . Parameters evaluated were uncorrected and best corrected visual acuity at day 1 , day 7 month I and month 2 and postoperative keratometric astigmatism at month 2. Data were collected on pre-designed data collection sheet, compiled and appropriate statistical analysis was done using computer based software (SPSS computer program). Postoperative visual outcome were calculated and compared between the 
two groups. Unpaired " $\mathrm{t}$ " test was done to determine the difference of postoperative visual status. A probability $\mathrm{P}$ of equal or less than 0.05 was considered significant. $\mathrm{P}$ value $<0.001$ was considered as highly significant and $P$ value $>0.05$ was considered non-significant.

\section{Results}

A total of 60 eyes of cataract patients were included in the study of which 30 eyes of cataract patients were randomly selected for suture less nonphaco SICS with PCIOL and 30 eyes of cataract patients were for conventional ECCE with PCIOL.

Table 1: Age distribution in SICS group $(\mathrm{n}=30)$ and ECCE group $(\mathrm{n}=30)$

\begin{tabular}{lccc}
\hline Age in year & $\begin{array}{c}\text { SICS group } \\
(\mathbf{n = 3 0})\end{array}$ & $\begin{array}{c}\text { ECCE group } \\
(\mathbf{n = 3 0 )}\end{array}$ & Total \\
\hline 51 to 60 Years & $20(66.7 \%)$ & $18(60.0 \%)$ & $\mathbf{3 8}$ \\
61 to 70 Years & $10(33.3 \%)$ & $12(40.0 \%)$ & $\mathbf{2 2}$ \\
Total & $\mathbf{3 0}(\mathbf{1 0 0 . 0} \%)$ & $\mathbf{3 0}(\mathbf{1 0 0 . 0} \%)$ & $\mathbf{6 0}$ \\
Mean \pm SD & $58.83 \pm 5.55$ & $58.77 \pm 6.56$ & \\
\hline
\end{tabular}

ns=not significant; $\mathrm{P}$ value was $>0.05$ which was calculated by unpaired "t" test

Table 1 shows age distribution in both study group. There were 20(66.7\%) patients between the years 51 to 60 and $10(33.3 \%)$ patients between the 61 to 70 years in SICS group. In ECCE group there were 18 patients (60\%) between the years 51 to 60 and $12(40 \%)$ patients

Table 2: Distribution of unaided visual acuity in SICS and ECCE group at different postoperative intervals

\begin{tabular}{|c|c|c|c|c|}
\hline $\begin{array}{l}\text { Postoperative } \\
\text { intervals }\end{array}$ & $\begin{array}{l}\text { Uncorrected } \\
\text { visual acuity }\end{array}$ & $\begin{array}{c}\text { SICS Group } \\
(\mathrm{n}=\mathbf{3 0})\end{array}$ & $\begin{array}{c}\text { ECCE Grour } \\
(n=30)\end{array}$ & Pvalue \\
\hline \multirow[t]{4}{*}{ Day 1} & $>6 / 9$ & $7(23.3 \%)$ & $0(0.0 \%)$ & \\
\hline & $6 / 12-6 / 18$ & $14(46.7 \%)$ & $(30.3 \%)$ & $<0.01^{*}$ \\
\hline & $6 / 24-6 / 36$ & $8(26.7 \%)$ & $16(53.3 \%)$ & \\
\hline & $<6 / 60$ & $1(3.3 \%)$ & $5(16.7 \%)$ & \\
\hline \multirow[t]{4}{*}{ Day 7} & $>6 / 9$ & $10(33.3 \%)$ & $1(3.3 \%)$ & \\
\hline & $6 / 12-6 / 18$ & $15(50.0 \%)$ & $12(40.0 \%)$ & $<0.001^{*}$ \\
\hline & $6 / 24-6 / 36$ & $5(16.7 \%)$ & $14(46.7 \%)$ & \\
\hline & $<6 / 60$ & $0(0.0 \%)$ & $3(10.0 \%)$ & \\
\hline \multirow[t]{4}{*}{ Month 1} & $>6 / 9$ & $14(46.7 \%)$ & $5(16.7 \%)$ & \\
\hline & $6 / 12-6 / 18$ & $15(50.0 \%)$ & $11(36.7 \%)$ & $<0.001^{*}$ \\
\hline & $6 / 24-8 / 36$ & $1(3.3 \%)$ & $12(40.0 \%)$ & \\
\hline & $<6 / 60$ & $0(0.0 \%)$ & $2(6.7 \%)$ & \\
\hline \multirow[t]{4}{*}{ Month 2} & $>6 / 9$ & $15(50.0 \%)$ & $9(30.0 \%)$ & \\
\hline & $6 / 12-6 / 18$ & $14(46.7 \%)$ & $14(46.7 \%)$ & $<0.01^{*}$ \\
\hline & $6 / 24-6 / 36$ & $1(3.3 \%)$ & $5(16.7 \%)$ & \\
\hline & $<6 / 60$ & $0(0.0 \%)$ & $2(6.7 \%)$ & \\
\hline Mean+ SD & & $1.80+0.71$ & $3.02+2.28$ & \\
\hline
\end{tabular}

*Significant $(\mathrm{P}<0.01)$ \& '.. = Highly significant $(\mathrm{P}<0.001)$ with unpaired t test; Scoring 6/6, 6/9, 6/12,6/18, 6/24, 6/36, 6/60 as value $1,1.5,2,3,4,6,10$ respectively, mean value calculated in both group and unpaired $t$ test was done. between the years 61 to 70 . Mean age distribution $(58.83 \pm 5.55 \& 58.77 \pm 6.56)$ was similar in both groups, making the study group more representative.

Table 2 Shows the unaided vision in both SICS \& ECCE group at different postoperative intervals. At day-7 and month -1 postoperatively the result appears highly significant between the two groups with unpaired ' $t$ ' test. At day 1 and month 2 also shows the significant result between the 2 groups.

Table 3 shows the best corrected visual acuity in SICS and ECCE group at different postoperative intervals. At day 7 and month 1 postoperatively the result appears highly significant between the two groups with unpaired ' $t$ ' test. At day 1 and month 2 also shows the significant result between the 2 groups.

Table 3: Distribution of best corrected visual acuity in SICS and ECCE group at different postoperative intervals

\begin{tabular}{|c|c|c|c|c|}
\hline $\begin{array}{l}\text { Postoperative } \\
\text { intervals }\end{array}$ & $\begin{array}{l}\text { Uncorrected } \\
\text { visual acuity }\end{array}$ & $\begin{array}{c}\text { SICS Group } \\
(\mathrm{n}=\mathbf{3 0})\end{array}$ & $\begin{array}{c}\text { ECCE Group } \\
(\mathrm{n}=\mathbf{3 0})\end{array}$ & p P value \\
\hline \multirow[t]{4}{*}{ Day 1} & $>6 / 9$ & $11(36.7 \%)$ & $7(23.3 \%)$ & \\
\hline & $6 / 12$ to $6 / 18$ & $18(60.0 \%)$ & $18(60.0 \%)$ & $<0.05^{*}$ \\
\hline & $6 / 24$ to $6 / 36$ & $1(3.3 \%)$ & $5(16.7 \%)$ & \\
\hline & $<6 / 60$ & $0(0.0 \%)$ & $0(0.0 \%)$ & \\
\hline \multirow[t]{4}{*}{ Day 7} & $>6 / 9$ & $14(46.7 \%)$ & $8(26.7 \%)$ & \\
\hline & $6 / 12$ to $6 / 18$ & $16(53.3 \%)$ & $21(70.0 \%)$ & $<0.001 * *$ \\
\hline & $6 / 24$ to $6 / 36$ & $0(0.0 \%)$ & $1(3.3 \%)$ & \\
\hline & $<6 / 60$ & $0(0.0 \%)$ & $0(0.0 \%)$ & \\
\hline \multirow[t]{4}{*}{ Month 1} & $>6 / 9$ & $16(53.3 \%)$ & $8(26.7 \%)$ & \\
\hline & $6 / 12$ to $6 / 18$ & $14(46.7 \%)$ & $20(66.7 \%)$ & \\
\hline & $6 / 24$ to $8 / 36$ & $0(0.0 \%)$ & $2(6.7 \%)$ & $<0.01^{*}$ \\
\hline & $<6 / 60$ & $0(0.0 \%)$ & $0(0.0 \%)$ & \\
\hline \multirow[t]{4}{*}{ Month 2} & $>6 / 9$ & $25(83.3 \%)$ & $21(70.0 \%)$ & \\
\hline & $6 / 12$ to $6 / 18$ & $5(16.7 \%)$ & $9(30.0 \%)$ & \\
\hline & $6 / 24$ to $6 / 36$ & $0(0.0 \%)$ & $0(0.0 \%)$ & $<0.01^{*}$ \\
\hline & $<6 / 60$ & $0(0.0 \%)$ & $0(0.0 \%)$ & \\
\hline Mean+ SD & & $1.28 \pm 39$ & $1.62 \pm 0.50$ & \\
\hline
\end{tabular}

*Significant $(\mathrm{P}<0.01) \& \cdot \cdot=$ Highly significant $(\mathrm{P}<0.001)$ with unpaired t test; Scoring 6/6, 6/9, 6/12,6/18, 6/24, 6/36, 6/60 as value $1,1.5,2,3,4,6,10$ respectively, mean value calculated in both group and unpaired $t$ test was done.

Table 3 shows the best corrected visual acuity in SICS and ECCE group at different postoperative intervals. At

Table 4: Distribution of uncorrected visual acuity of 6/9 or better in SICS \& ECCE group at following postoperative interval

\begin{tabular}{lcc}
\hline $\begin{array}{l}\text { Postoperative } \\
\text { interval }\end{array}$ & $\begin{array}{c}\text { SICS group } \\
(\mathbf{n}=\mathbf{3 0})\end{array}$ & $\begin{array}{c}\text { ECCE group } \\
(\mathbf{n}=\mathbf{3 0})\end{array}$ \\
\hline Day 1 & $7(23.3 \%)$ & $0(0.0 \%)$ \\
Day 7 & $10(33.3 \%)$ & $1(3.3 \%)$ \\
Month 1 & $14(46.6 \%)$ & $5(16.6 \%)$ \\
Month 2 & $15(49.9 \%)$ & $9(29.9 \%)$ \\
\hline
\end{tabular}


day 7 and month 1 postoperatively the result appears highly significant between the two groups with unpaired ' $t$ ' test. At day 1 and month 2 also shows the significant result between the 2 groups.

Table 4 shows distribution of unaided visual acuity of $6 / 9$ or better in SICS and ECCE at different postoperative intervals. In SICS group out of 30 patients, 7 cases (23.3\%) acquired unaided vision 6/9 at day 1,10 patients $(33.3 \%)$ at day 7,14patients $(46.6 \%)$ at month 1 and 15 patients (49.9\%) at month 2. On the other hand in ECCE group no patient was found with vision $\geq 6 / 9$ at day 1 and only one patient with vision $\geq$ $6 / 9$ at day 7.At month 1 there were 05 patients $(16.6 \%)$, and at month 2 there were 09 patients $(29.9 \%)$ with vision $\geq 6 / 9$. Nearly $50 \%$ patients of SICS group achieve unaided vision of $\geq 6 / 9$ within the follow up period of 02 months.

\section{Discussion}

Non-phaco small incision cataract surgery is one of the modem technique of extra capsular cataract extraction?. The postoperative aphakic correction in both ICCE and ECCE were made with different techniques including thick lenseswhich resulted in marked visual problems. Considering hazards of spectacles and cosmetic contact lenses, scarcity of comes for epikeratoplasty, IOL now evolved as the most comfortable and economic management of aphakia ${ }^{10}$. In this modem world ECCE with PCIOM has almost been replaced by phaco surgery withinbag IOM. However, as it requires very expensive instruments, long learning curve and highly trained maintenance personnel in phaco surgery, ophthalmologists again were trying to shift to a new direction of SICS-a very simple technique with all the beauties of modem phaco surgery ${ }^{11}$.

Manual SICS and related nonphaco emulsification techniques are now practiced by many surgeons worldwide, which do not depend on expensive and failure prone machinery and not require a heavy financial investment ${ }^{12}$. SICS could be the preferred technique for community ophthalmology to combat the huge backlog in developing country like Bangladesh. Ophthalmologists can adopt this technique after a training for a short duration. Again as it does not require advanced infrastructure, it can be practiced easily even in a rural setup anywhere in the country. Considering these situations, this study has been performed a comparative study of nonphaco SICS with conventional ECCE. At the beginning of this study, patients were selected irrespective of preoperative visual status for both SICS and conventional ECCE.
The selected 60 patients were divided into two groups and 30 eyes are in each. 30 eyes had IOM implantation following conventional ECCE with a sclero corneal incision and 30 eyes had IOM implantation through a small incision scleral tunnel without sutures after manual nucleus expression.

In this study uncorrected visual acuity of greater than or equal to $6 / 9$ was achieved in $7(23.3 \%)$ cases on the day land $10(33.3 \%)$ cases at the 1 st week. Adileet al ${ }^{12}$ found $6 / 9$ or greater visual acuity in $25 \%$ of patients in 1 st day and $33.0 \%$ of patient at day 7 . In this study it has found the same result of visual acuity $\geq 6 / 9$ with lower number of patient compare to their result. It may be due to slight corneal oedema which disappears later on and at day 7 the observation becomes more-or less similar.

Unaided visual acuity of $6 / 9$ or more was found in 15 cases $(50 \%)$ in SICS and 9 cases $(30 \%)$ in ECCE in this study at month 2 . Chadha etal ${ }^{13}$ found unaided vision of $\geq 6 / 9$ in $51.3 \%$ patients of SICS group and $25.0 \%$ patients of ECCE group at follow up period of 2 months. Adileet $\mathrm{a}^{12}$ found the similar result following SICS and the result was better than ECCE. The results of these two study are also similar to this study. Best-corrected visual acuity of a 6/9 was achieved in $11(36.7 \%)$ cases at day 1 in SICS group and 7(23.3\%) cases at day1 in ECCE group. Vision at or more than 6/9 was found more in SICS cases than in ECCE cases at day 1 in this study. Minassianet $\mathrm{a}^{14}$ achieved best corrected visual acuity 6/9 in 35(87.5\%) number of cases by modified Blumenthals technique. Gogateet $\mathrm{al}^{15}$ found corrected visual acuity $6 / 9$ or better in $87.15 \%$ of cases. In this study best corrected visual acuity after 2 -month $\geq 6 / 9$ was achieved in $25(83.3 \%)$ cases. Various studies have reported that a $3.0 \mathrm{~mm}$ incision produces about $0.26 \mathrm{D}$ againsttherule astigmatism while a $4.00 \mathrm{~mm}$ incision induces a $0.77 \mathrm{D}$ and $5.00 \mathrm{~mm}$ incision induces over $1 \mathrm{D}$ of against the rule astigmatism $^{16}$.

Hence this study with nonphaco SICS in which incision was approximately 6 to $6.5 \mathrm{~mm}$ length, was not completely free of astigmatism. But comparatively less astigmatism was induced in SICS that is $(1.04 \pm 0.67)$ than that of conventional ECCE with sutures $(1.59 \pm$ $0.46)$. Gogateet $\mathrm{al}^{15}$ found average astigmatism (1.20 \pm $0.60)$ in SICS which was more or less nearer to the present study. Significantly less astigmatism was observed by Watson and Sunderraj ${ }^{17}$ in SICS ( $0.68 \pm$ $0.52)$ than in ECCE with sutures $(1.50 \pm 0.82)$ and Oshika etal ${ }^{18}$ noted astigmatism in between $(0.5 \mathrm{D} \pm 1$ D) in SICS while in standard ECCE astigmatism was 
$1.0 \mathrm{D}$ to $1.5 \mathrm{D}$. These two studies correlates with my findings only in extra capsular cases but not in SICS cases. Conrad-Hengerer et $\mathrm{al}^{19}$ had study with $6 \mathrm{~mm}$ tunnel and manual nucleus delivery in 70 eyes and reported astigmatism of $0.5 \mathrm{D}$ or better in $76.6 \%$ cases. This study shows a bit more astigmatism than their study, may be due to dose limbal incision and larger corneal entry wound. Haberleet $\mathrm{a}^{20}$ studied on 70 eyes without sutures. They found late mean astigmatism up to 3 years follow up was $2.05 \pm 1.16 \mathrm{D}$ for suture less wound closure which is quite bigger than this study.

In manual SICS, the length of the internal opening is approximately $1 \mathrm{~mm}$ longer on either side of the incision compared to external opening. Thus a $6 \mathrm{~mm}$ external wound will actually have $8 \mathrm{~mm}$ internal opening which may explain a slightly higher astigmatism seen with small incision ECCE with rigid PMMA lens. From present study it was evident that patient who underwent sutureless non-phaco SICS experienced faster visual recovery than those who had conventional ECCE with sutures. There were significantly more patients with uncorrected visual acuity $\geq 6 / 9$ in non phaco SICS group at all post-operative intervals. Patients with best corrected visual acuity were significantly more in SICS group in early post-operative period. Better visual acuity in SICS group may be due to less astigmatism in sutureless non phaco SICS technique. Closed chamber surgery in a normal physiological condition without much disturbing the anatomical structures and less manipulation of uveal tissue during surgery may also contribute to the good visual outcome in the immediate post-operative period ${ }^{21}$.

There are some limitation of this study. Visual acuity measured by Snellen test types may be influenced by various factors, namely refractive status of the eye, luminance, contrast, pupil size, meridional variation and exposure duration. As because most of the study cases were illiterate so Mandolt's broken ring was used to measure visual acuity. These repetitive pattern also may spuriously resolved in defocused state of the eye, giving the false impression of visual status. If these conditions may be improved including the site and measurement procedure, more correct and improved result may be found. Because of above mentioned causes, some of the findings might be influenced which could be avoided if limiting factors could be eliminated.

\section{Conclusion}

In conclusion this study support the reasons for switching over to non-phaco small incision cataract surgery from conventional method of ECCE with sutures. Uncorrected visual acuity in SICS cases were better than that of ECCE cases with sutures during the period of follow up.So postoperative visual acuity without optical correction is very important for the working class of people. Ophthalmologist performing conventional ECCE at present can shift to the non-phaco SICS easily and can increase their volume of surgery maintaining high quality. Considering these facts non-phaco SICS is more appropriate for developing country.

\section{References}

1. Hennig A. Sutureless non-phaco cataract surgery: a solution to reduce worldwide cataract blindness. Community Eye Health. 2003;16(48):49-51

2. Thomas R, Kuriakose T, George R. Towards achieving small-incision cataract surgery $99.8 \%$ of the time. Indian journal of ophthalmology. 2000;48(2):145

3. Gogate P, Optom JJ, Deshpande S, Naidoo K. Meta-analysis to compare the safety and efficacy of manual small incision cataract surgery and phacoemulsification. Middle East African journal of ophthalmology. 2015;22(3):362.

4. Garg P, Mahesh S, Bansal AK, Gopinathan U, Rao GN. Fungal infection of sutureless self-sealing incision for cataract surgery. Ophthalmology. 2003;110(11):2173-7.

5. Zawar SV, Gogate P. Safety and efficacy of temporal manual small incision cataract surgery in India. European journal of ophthalmology. 2011;21(6):748-53

6. Jaggernath J, Gogate P, Moodley V, Naidoo KS. Comparison of cataract surgery techniques: safety, efficacy, and cost-effectiveness. European journal of ophthalmology. 2014;24(4):520-6.

7. Gurung A, Karki DB, Shrestha S, Rijal AP. Visual outcome of conventional extracapsular cataract extraction with posterior chamber intraocular lens implantation versus manual small-incision cataract surgery. Nepalese Journal of Ophthalmology. 2009;1(1):13-9.

8. Jauhari N, Chopra D, Chaurasia RK, Agarwal A. Comparison of surgically induced astigmatism in various incisions in manual small incision cataract surgery. International journal of ophthalmology. 2014;7(6):1001.

9. George R, Rupauliha P, Sripriya AV, Rajesh PS, Vahan PV, Praveen S. Comparison of endothelial cell loss and surgically induced astigmatism following conventional extracapsular cataract surgery, manual small-incision surgery and phacoemulsification. Ophthalmic epidemiology. 2005;12(5):293-7.

10. Gogate PM, Kulkarni SR, Krishnaiah S, Deshpande RD, Joshi SA, Palimkar A, Deshpande MD. Safety and efficacy of phacoemulsification compared with manual small-incision cataract surgery by a randomized controlled clinical trial: six-week results. Ophthalmology. 2005;112(5):869-74.

11. Kahraman G, Amon M, Franz C, Prinz A, Abela-Formanek C. Intraindividual comparison of surgical trauma after bimanual microincision and conventional small-incision coaxial phacoemulsification. Journal of Cataract \&Refractive Surgery. 2007;33(4):618-22.

12. Adile SL, Chandrakar AK, LalWani D, Dave K, Agarwal R. Comparison of small incision Non phaco with standard ECCE: 
Post-operative astigmatism and visual recovery. 58th Annual Conference of All India Ophthalmological Society, Jan 6th -9th, 2000;p274.

13. Chadha V,, Ghosh B, Goswami A, Adhar S, Mal A.Modified Blumenthal's Technique vs conventional ECCE: A comparative study. Ophthalmology abstracts 59th Annual conference of All India Ophthalmological societies, 2001:325

14. Minassian DC, Rosen P, Dart JK, Reidy A, Desai P, Sidhu M. Extracapsular cataract extraction compared with small incision surgery by phacoemulsification: a randomised trial. British Journal of Ophthalmology. 2001;85(7):822-9.

15. Gogate PM, Deshpande M, Wormald RP, Deshpande R, Kulkarni SR. Extracapsular cataract surgery compared with manual small incision cataract surgery in community eye care setting in western India: a randomised controlled trial. British Journal of Ophthalmology. 2003;87(6):667-72.

16. Natchiar G, Manual Small Incision Cataract Surgery, In: MANUAM SICS in comparison with phaco emulsification, Dec 2000;3-6.
17. Watson A, Sunderraj P. Comparison of small-incision phacoemulsification with standard extracapsular cataract surgery: postoperative astigmatism and visual recovery. Eye. 1992;6(6):626.

18. Oshika T, Yoshimura K, Miyata N. Postsurgical inflammation after phacoemulsification and extracapsular extraction with soft or conventional intraocular lens implantation. Journal of Cataract \& Refractive Surgery. 1992;18(4):356-61.

19. Conrad-Hengerer I, Al Juburi M, Schultz T, Hengerer FH, Dick HB. Corneal endothelial cell loss and corneal thickness in conventional compared with femtosecond laser-assisted cataract surgery: three-month follow-up. Journal of Cataract \& Refractive Surgery. 2013;39(9):1307-13.

20. Haberle H, Anders N, Anloni HJ, Pham DT, Wollensak J, 3 $\& 1 / 2$ years experiences with ECCE with tunnel incision, Ophthalmology, 1997;94(1):12-15.

21. Abell RG, Kerr NM, Vote BJ. Femtosecond laser-assisted cataract surgery compared with conventional cataract surgery. Clinical \& experimental ophthalmology. 2013;41(5):455-62 